\title{
EDUCAÇÃO, ENSINO E DOCÊNCIA: REFLEXÕES E PERSPECTIVAS
}

\author{
Stela Marques ${ }^{1}$ \\ Thiago Oliveira ${ }^{2}$
}

\section{Resumo}

O objetivo deste artigo é a análise da profissão docente em suas diversas perspectivas educacionais. O pressuposto para a construção do artigo foi cogitar sobre como a educação, o ensino e a docência podem se materializar de maneira crítica na formação do cidadão pleno, isto é, o sujeito autônomo que pensa por si mesmo. Busca-se uma prática educativa da possibilidade, uma educação que viabilize um mundo mais justo e equânime que não se rende às amarras da massificação. $\mathrm{Na}$ contemporaneidade percebe-se uma perda patente das relações humanas dentro do processo educacional, sobretudo no que tange à relação docência e ensino. Procura-se diferenciar o que, de fato, é educação e o que é ensino em uma análise alicerçada na teoria pedagógica e na história da educação. Dentro dessa perspectiva busca-se a reiteração da importância da formação docente e do papel do professor, num movimento de promoção de uma educação de intercâmbio crítica e libertadora.

Palavras chaves: Educação; Ensino; Formação Docente; Professor

\section{INTRODUÇÃO}

$\mathrm{Na}$ atualidade, debates sobre educação, ensino e docência são omnipresentes, seja na esfera dos atores educativos, seja na esfera política ou da própria sociedade. Há um consenso generalizado de que o desenvolvimento de um país está intimamente ligado à qualidade da

${ }^{1}$ Professora Adjunta e Pesquisadora. Doutora em Educação. Endereço profissional: Pontifícia Universidade Católica de Minas Gerais, Programa de Pós-graduação em Educação, Edifício Emaús, Avenida Itaú, 505, 3. andar, CEP 30.535-012, Belo Horizonte-MG, Brasil. Endereço eletrônico: sm.pucminas@ gmail.com.

${ }^{2}$ Doutorando em Educação. Mestre em Educação. Endereço profissional: Pontifícia Universidade Católica de Minas Gerais, Programa de Pós-graduação em Educação, Edifício Emaús, Avenida Itaú, 505, 3. ${ }^{\circ}$ andar, CEP 30.535-012, Belo Horizonte-MG, Brasil. Endereço eletrônico: tlsoliveira@ yahoo.com.br 
MARQUES, S.; OLIVEIRA, T.

sua educação. Daí a constância compreensível na discussão dos males que afligem a escola e o processo ensino-aprendizagem, que atingem, por seu turno, professores, família, comunidades, e que consequentemente afeta o modo como entendemos a educação, o ensino e a docência na era da globalização e da tecnologia. Porém, antes de mais, importa definir estes termos que, embora possam ser usados de forma indistinta, têm essências díspares. Além disso, os conceitos influenciam e são afetados por instâncias múltiplas, mutáveis de acordo com a conjuntura social, econômica e política de dado momento.

\title{
2 ENSINO E EDUCAÇÃO
}

Existe entre ensino e educação uma diferença basilar. Enquanto que o primeiro se refere principalmente ao ensino de conteúdos e conhecimentos, o segundo possui contornos mais complexos, que envolvem aprendizagens curriculares, mas também valores e atitudes, que visam formar melhor o indivíduo na sua totalidade. No sentido mais amplo, educação vai além do ensinar, envolve a provisão de possibilidades de autoconhecimento e valores éticos. Ensino centra-se na transmissão de conhecimento enquanto educação visa a transmissão dos valores necessários ao convívio, manutenção e desenvolvimento da sociedade como um todo, de forma a fazê-la funcionar como um único corpo orgânico. Como nos explica Spohr,

\begin{abstract}
O ensino, que é instrução, se dirige ao intelecto e o enriquece. A educação visa os sentimentos e os põe sob o controle da vontade. Assim, pode-se adquirir um ótimo caráter de conduta com pouca instrução, o que já permite viver feliz. Por outro lado, pode ser cultivado, sem nenhuma educação, um péssimo caráter de conduta, que será tanto pior quanto mais instrução houver - é aqui que se enquadram todos os corruptos e grandes golpistas que tiveram muito ensino e pouca educação, e que nunca serão realmente felizes. (SPOHR, 2006)
\end{abstract}

Por seu lado, Brandão corrobora esta posição afirmando que,

O homem que transforma, com o trabalho e a consciência, partes da natureza em invenções de sua cultura, aprendeu com o tempo a transformar partes das trocas feitas no interior desta cultura em situações sociais de aprender-ensinar e aprender: em educação. Na espécie humana, a educação não continua apenas no trabalho da vida. Ela se instala dentro de um domínio propriamente humano de trocas: de símbolos, de intenções, de padrões de cultura e de relações de poder. Mas, a seu modo, ela continua no Homem o trabalho da natureza de fazê-lo evoluir, de torná-lo mais humano. (2007, p. 14) 
EDUCAÇÃO, ENSINO E DOCÊNCIA: REFLEXÕES E PERSPECTIVAS

Note-se, portanto, o sentido mais amplo da educação, o de capacitar o indivíduo para o autoconhecimento e para a transmissão dos valores morais, culturais e cívicos que sustentam a sociedade. Esse poder de capacitação social é reforçado ainda mais claramente por Saviani,

Se a existência humana não é garantida pela natureza, não é dádiva natural, mas tem de ser produzida pelos próprios homens, sendo, pois, um produto de trabalho, isso significa que o homem não nasce homem. Ele forma-se homem. Ele não nasce sabendo produzir-se como homem. Ele necessita aprender a ser homem, precisa aprender a produzir sua própria existência. Portanto, a produção do homem é, ao mesmo tempo, a formação do homem, isto é, um processo educativo. A origem da educação coincide, então, com a origem do homem mesmo. (2007, p. 154)

Por outro lado, a educação auxilia ainda o indivíduo a tomar consciência de si mesmo e do que o rodeia,

\begin{abstract}
A consciência do mundo e a consciência de si como ser inacabado necessariamente inscrevem o ser consciente de sua inclusão num permanente movimento de busca. É na inconclusão do ser, que se sabe como tal, que se funda a educação como processo permanente. [...] Não importa com que faixa etária trabalhe o educador ou a educadora. O nosso é um trabalho realizado com gente, miúda, jovem ou adulta, mas gente em permanente processo de busca. (FREIRE, 2002, p. 64)
\end{abstract}

De tudo o que se discute hoje sobre a educação, pode-se concluir que não há uma forma única nem um único modelo de educação. Nóvoa (1992) defende que a escola não é o único lugar onde ela acontece, nem o ensino escolar é a sua única prática, nem o professor o seu único praticante. Em outras palavras, a educação revela-se de forma diferente, tanto quanto o mundo a que se refere. Brandão (2007) exemplifica as diferentes possibilidades: em pequenas sociedades tribais de povos caçadores, agricultores ou pastores nômades; em sociedades camponesas, em países desenvolvidos e industrializados; em mundos sociais sem classes, de classes ou em tipos de sociedades e culturas sem Estado. Para este autor, a educação existe em cada povo e entre povos que submetem e dominam outros povos, usando a educação como forma de dominância. Da família à comunidade, a educação é disseminada em todos os mundos sociais, desde as iniciais práticas do aprender, sem classes de alunos, sem livros e sem professores até as escolas, salas, professores e métodos pedagógicos. A educação pode existir livre e,

ser uma das maneiras que as pessoas criam para tornar comum, como saber, como ideia, como crença, aquilo que é comunitário como bem, como trabalho ou como vida. Ela pode existir imposta por um sistema centralizado de poder, que usa o saber e o controle sobre o saber como armas que reforçam a desigualdade entre os 
MARQUES, S.; OLIVEIRA, T.

homens, na divisão dos bens, do trabalho, dos direitos e dos símbolos. (BRANDÃO, 2007, p. 10)

A educação reflete o modo de vida dos grupos sociais que a criam e recriam em sua sociedade. As diferentes formas de educação reproduzem, por sua vez, o saber que atravessa esses mesmos grupos sociais, seus códigos sociais de conduta, suas regras laborais, sua arte, religião, artesanato ou tecnologia, tudo o que um povo necessita para reinventar constantemente a vida do grupo e que ajuda a explicar às futuras gerações a necessidade da existência de sua ordem. Nesta perspectiva, cabe refletir sobre o papel da educação no contexto brasileiro, na conjuntura socioeconômica da presente era da informação.

A mesma reflexão é imprescindível no âmbito do ensino brasileiro. Como vimos anteriormente, o conceito de ensino focaliza a transmissão de conteúdos curriculares e de conhecimentos, e isso coloca em evidência tanto as vertentes do processo de ensinoaprendizagem quanto seus pontos fortes e pontos fracos. Analisando os fatores que contribuem para o sucesso escolar, é aceitável considerar o planejamento curricular cuidadoso como um dos principais responsáveis por esse sucesso, elemento fundamental da sistematização dos saberes, como explica Saviani,

\begin{abstract}
A educação escolar está ligada ao desenvolvimento e ao acesso da população a um saber sistematizado, de base científica. Para ter acesso a um saber não elaborado, a população não precisa de escola, parte de suas próprias vivências. A cultura letrada não se aprende de forma espontânea, tem que haver processos sistematizados, formais, é esse o papel fundamental da escola. Os currículos têm de ser organizados levando em conta esse dado e buscando selecionar, no conjunto dos conhecimentos elaborados da cultura letrada, os elementos fundamentais que permitam às crianças e aos jovens, adquirindo-os, ingressar nesse universo e ganhar autonomia para serem capazes de por si próprios aprender e conhecer outros aspectos. (2008, p. 3)
\end{abstract}

Se a sistematização cuidadosa do conhecimento é fundamental para que os indivíduos se apropriem da cultura letrada vigente, importa ainda salientar a urgência do desenvolvimento da autonomia, posição que já era defendida no século XIX: “entretanto, não é suficiente treinar as crianças; urge que aprendam a pensar" (KANT, 1803, p. 69). Freire (2002, p. 78) assinala ainda que essa é uma "difícil passagem ou caminhada da heteronomia para a autonomia”, já que o contexto escolar está (ainda) organizado para educar, de forma homogênea, grupos heterogêneos de indivíduos. Exemplo disso é a globalização acentuada do final do século XX, que reforçou o conceito de "uma educação igual para todos".

Ora, à partida, esta estruturação do ensino causa constrangimentos e restrições, sejam eles de ordem logística ou gerencial, sejam eles de ordem política, social ou cultural. Assim, é 
EDUCAÇÃO, ENSINO E DOCÊNCIA: REFLEXÕES E PERSPECTIVAS

possível observar que os currículos oferecem poucas ou nenhumas possibilidades de desenvolvimento da autonomia, sobretudo quando se verifica que, por um lado, os docentes estão sob pressão para transmitir um rol de conteúdos, e por outro lado, os alunos estão perpetuamente envoltos numa cultura escolar baseada na memorização e em resultados.

Importa, pois, refletir se esta cultura escolar predominante no século $\mathrm{XX}$ atende ainda os interesses da sociedade do século XXI. Importa, ainda, analisar formas de ensino que contribuam na formação de indivíduos verdadeiramente preparados para as vicissitudes da realidade atual, que apresenta exigências e problemas diferentes de tempos passados. E essa análise passa pela redefinição do papel do docente, sua formação inicial e continuada e pelo apoio que deverá ter para exercer a sua função de forma contextualizada e eficaz. Para entender melhor o caminho já percorrido, vejamos os contornos mais expressivos da evolução da educação.

\subsection{Educação tradicional}

Durante o século XX, o paradigma educativo dominante era o tradicional, aquele que privilegia a obediência, a memorização e a repetição de conteúdos. Enraizada na sociedade de classes escravistas da Idade Antiga, destinada a uma pequena minoria, a educação tradicional iniciou seu declínio no movimento renascentista, porém, prevaleceu até hoje.

\section{2 Educação Nova}

A educação nova, que emerge primeiramente da obra de Rousseau, desenvolveu-se nos últimos dois séculos e levou a múltiplas conquistas, sobretudo no campo das ciências da educação e das metodologias de ensino. O conceito de John Dewey de "aprender fazendo" e as Técnicas Freinet (por exemplo, aula passeio, texto livre, imprensa escolar, auto-avaliação), são aquisições decisivas na história da pedagogia (GADOTTI, 2000).

\section{3 Educação Internacionalizada}

Em meados do século XX, educadores e políticos conceptualizaram uma educação internacionalizada, sob os auspícios da UNESCO (GODOTTI, 2000). Nesta altura, os países 
MARQUES, S.; OLIVEIRA, T.

mais desenvolvidos já haviam universalizado o ensino fundamental e erradicado o analfabetismo, impulsionados pelos sistemas nacionais de educação e seus inúmeros planos educativos, que reduziam custos e ampliavam benefícios. Como resultado, verifica-se que a estrutura básica de todos os sistemas educacionais é genericamente uniforme. O fenômeno da globalização que se acentuou no final do século XX reforçou ainda mais o conceito de uma educação igual para todos, como parâmetro curricular comum e não mais como princípio de justiça social.

\section{4 Educação Popular}

Este paradigma, inicialmente inspirado no trabalho de Paulo Freire na década de 1960, encontrou sua categoria fundamental na conscientização. A prática e a reflexão sobre a prática levaram à incorporação de outra categoria importante, a organização, o que significa que para transformar, é essencial ter consciência e organização.

A educação popular de hoje segue principalmente em duas direções: na educação pública popular (Estado) e na educação popular comunitária, na educação ambiental ou sustentável (sobretudo não governamental). A educação popular foi o primeiro grande passo para quebrar a hegemonia da educação tradicional, autoritária, vertical, na direção de maiores possibilidades de colaboração e parcerias com o Estado. Abriu-se, assim, espaço para a construção da educação pública popular, procurando tornar popular a educação oferecida pelo Estado. Segundo Gadotti (2000), a grande utopia da educação popular dos anos 50 visava a conquista do estado e a mudança radical da política econômica e social. Atualmente, verificase que a educação popular se dispersa em milhares de pequenas experiências, perdendo a sua grande unidade teórica, mas ganhando em diversidade. Esses pequenos grupos e movimentos representam as verdadeiras forças constituintes da nova sociedade, lutando nas mais variadas frentes: luta pela terra, direitos civis, direitos humanos, alfabetização, direito da mulher, luta de minorias étnicas, religiosas, culturais, movimentos ecológicos, por moradia, de crianças de rua, entre outros. Estes múltiplos movimentos encerram em si mesmo um novo entendimento da educação popular e do estado.

Por conseguinte, as conquistas democráticas levaram à fragmentação da educação. Se por um lado ela ganhou um novo ímpeto e incentivo estatal, visível em múltiplas políticas públicas, por outro lado, prevaleceu enquanto educação não formal, dissipando-se em incontáveis projetos. Se por um lado perdeu em unidade, ganhou em diversidade e conseguiu 
EDUCAÇÃO, ENSINO E DOCÊNCIA: REFLEXÕES E PERSPECTIVAS

incorporar-se ao pensamento pedagógico universal e orienta a atuação de muitos educadores espalhados pelo mundo.

A educação popular, enquanto modelo teórico conceituado tem oferecido alternativas como a reforma dos sistemas de escolarização pública. A vinculação da educação popular ao poder local e à economia popular abre, também, novas e inéditas possibilidades para a prática da educação.

O modelo teórico da educação popular, elaborado na reflexão sobre a prática da educação durante várias décadas, tornou-se, sem dúvida, uma das grandes contribuições da América Latina à teoria e à prática educativa em âmbito internacional. A noção de aprender a partir do conhecimento do sujeito, a noção de ensinar a partir de palavras e temas geradores, a educação como ato de conhecimento e de transformação social e a politicidade da educação são apenas alguns dos legados da educação popular à pedagogia crítica universal.

\section{5 Paradigmas holonômicos}

Os paradigmas holonômicos sustentam um princípio unificador do saber e do conhecimento, que foca o ser humano, valoriza o seu cotidiano, suas vivências, sua singularidade e contexto e categorias como: decisão, projeto, ruído, ambiguidade, finitude, escolha, síntese, vínculo e totalidade.

Etimologicamente, holos, em grego, significa todo e os novos paradigmas procuram centrar-se na totalidade. Por um lado, os paradigmas clássicos, delimitados pelo positivismo (que defende a ideia de que o conhecimento científico é a única forma de conhecimento verdadeiro, desconsiderando tudo que não pode ser comprovado cientificamente) e pelo marxismo (que defende a emancipação do proletariado, socialização dos meios de produção e a abolição das classes sociais), são marcados pela ideologia e lidam com categorias redutoras da totalidade. Por seu lado, os paradigmas holonômicos pretendem restaurar a totalidade do sujeito, valorizando a sua iniciativa, criatividade e complexidade.

Quando adota como fundamento da educação uma antropologia que concebe o indivíduo como um ser de essência contraditória, os paradigmas holonômicos almejam conservar todos os componentes da complexidade da vida. Para os seguidores, o imaginário e a utopia são os fatores centrais que edificam a sociedade e renunciam a tudo que possa extinguir o desejo, a paixão, o olhar e a escuta. Para os novos paradigmas, a história é 
MARQUES, S.; OLIVEIRA, T.

essencialmente possibilidade, em que o que vale é o imaginário (Durand). Sob diversas formas e com diferentes significados, essas categorias são encontradas em muitos intelectuais, filósofos e educadores: o sentido do outro, a curiosidade (Freire), a tolerância (Jaspers), a estrutura de acolhida (Ricoeur), o diálogo (Buber), a autogestão (Freinet), a desordem (Morin), a ação comunicativa, o mundo vivido (Habermas), a radicalidade (Heller), a empatia (Rogers), a questão de gênero (Viezzer), o cuidado (Boff), a esperança (Bloch), a alegria (Snyders), a unidade do homem contra as unidimensionalizações (Marcuse), etc. Vale ressaltar que existem divergências e nem todos estes autores se enquadrariam nos paradigmas holonômicos. Porém, as categorias aqui apontadas indicam uma perspectiva da educação, em que se procura buscar na unidade dos contrários e na cultura contemporânea uma direção do futuro, denominada de pedagogia da unidade (GADOTTI, 2000).

\section{EDUCAÇÃO E DOCÊNCIA}

A educação tradicional, que Paulo Freire denominou Educação Bancária visava a mera transmissão passiva de conteúdos do professor, entendido como aquele que possui e domina o saber, para o aluno, que era assumido como aquele que nada sabe. Então, a atuação docente do professor visa preencher com o saber a cabeça vazia de seus alunos, depositando conteúdos, como alguém deposita dinheiro num banco. A "concepção bancária da educação" (FREIRE, 1983, p.66) é um bom exemplo de educação antidialógica, uma situação que perpetua a contradição entre educador-educando. Esta concepção educativa define a ação do professor em dois momentos distintos: primeiro, o educador adquire conhecimentos para, num segundo momento em sala de aula, os transmitir aos alunos, que arquivam o que ouvem ou copiam, memorizando o conhecimento pronto.

É desta forma vertical e antidialógica que se educa para a passividade e não para o desenvolvimento do sentido crítico e a autonomia. Ainda segundo Freire, a mera narração ou dissertação perpetua a contradição entre educador e educando já que não promove a educação: "narração de conteúdos que, por isto mesmo, tendem a petrificar-se ou a fazer-se algo quase morto" (FREIRE, 1983, p. 65). Além disso, este modelo educativo aborda a realidade de forma retalhada e estática, sem dar importância alguma à experiência prévia do aluno: "desta maneira, a educação se torna um ato de depositar, em que os educandos são os depositários e o educador o depositante" (ibid., p. 66). Em suma, o educador é que educa, sabe, pensa, 
EDUCAÇÃO, ENSINO E DOCÊNCIA: REFLEXÕES E PERSPECTIVAS

disciplina, prescreve a opção, atua, escolhe o conteúdo programático, identifica a autoridade do saber com sua autoridade funcional, i.e., é o sujeito do processo. Os educandos, ao contrário, são educados, não sabem, são pensados, escutam docilmente, são disciplinados, seguem a prescrição, têm papel passivo, não são ouvidos, devem adaptar-se às determinações do educador, i.e., são meros objetos (ibid., p. 66-67).

Não será um exagero afirmar que este modelo de educação, dominante no século XX, continua bem presente nas escolas brasileiras da atualidade. Também parece oportuno refletir sobre as consequências da aplicação do modelo educativo do século XX na sala de aula do século XXI. Como ficou evidente no passado, as consequências de tratar o aluno como depósito de conhecimentos e a persistente ausência de uma consciência crítica podem ter impacto profundo na formação do cidadão contemporâneo. Porém, docentes de todos os níveis educativos insistem numa educação autoritária que inevitavelmente inibe a capacidade de questionamento e engessa a curiosidade, gerando cidadãos passivos e pouco preparados para pensar por si mesmos com segurança e autonomia, negando o indivíduo como sujeito de suas ações e como ser de opção.

Assim, emerge um questionamento levantado pelo próprio Paulo Freire, que entendia a educação bancária como prática da dominação. Isto significa que mantendo o educando na ingenuidade, ele se acomoda ao mundo de opressão e permanece na heteronomia, ou seja, na sujeição à vontade de terceiros ou coletividade (FREIRE, 1975). A mera transferência de conteúdos e a não participação do educando na produção do conhecimento tem como consequência imediata a desmotivação e falta de interesse em estudar o que é "passado" em sala de aula (FREIRE e SHOR, 1986, p. 15). Segundo Freire (1997), o termo evasão escolar é ideológico, pois pretende dar a entender que os alunos estão fora da escola por vontade deles, quando de fato eles são expulsos da escola, excluídos especialmente pela organização bancária. O termo correto é "expulsão escolar" (FREIRE, 1995, p. 46). Isso está intrinsecamente ligado ao despreparo científico e lacunas nos saberes e competências dos professores e à educação vinculada a uma ideologia elitista que não alfabetiza a partir da realidade do educando. A expulsão de um aluno da escola significa condená-lo ao silêncio, sobretudo se suas habilidades de leitura e escritas são pobres ou inexistentes, pois dificilmente poderá manter relações genuinamente dialógicas em um mundo que existe pela palavra, irá depender de ideias e posicionamentos de outrem e, por consequência, não poderá conquistar a própria autonomia. Este panorama é preocupante em qualquer nível de ensino. A questão da 
MARQUES, S.; OLIVEIRA, T.

"expulsão escolar" no nível superior tem um conjunto de motivações igualmente abrangente, como por exemplo, dificuldades financeiras ou falta de apoio educativo familiar.

Neste contexto educacional, o professor assume o papel de mero narrador da realidade, algo imutável, estático, compartimentado e bem comportado. Aliás, há uma evidente preocupação com a questão comportamental, que não é mais do que o reflexo da situação social e política predominante ao longo do século $\mathrm{XX}$, em que o objetivo recorrente era formar cidadãos passivos, obedientes, patriotas. Para tal, o modelo de educação tradicional foi claramente bem sucedido, pelo menos até à década de 1980, no período pós-regime da Ditadura Militar (1964-1985), altura em que o paradigma do modelo tradicional se tornou ineficaz: em tese, a sociedade tornou-se democrática, sobretudo com a aprovação da Constituição Federal de 1988 e estabelecimentos de princípios democráticos.

Esta mudança também teve repercussões nos objetivos educacionais, já que, em tese, uma sociedade democrática requer que seus cidadãos sejam críticos e criativos, capazes de compreender problemas, teorias e argumentos, reagindo a eles de forma concludente:

\begin{abstract}
Um estudante que tem um conhecimento sólido de física, história, das línguas cultas mais significativas, de filosofia, geografia, matemática, etc., e que tem instrumentos críticos que the permitem avaliar criativamente ideias, será um cidadão bem equipado para enfrentar os desafios do futuro. Um estudante que sabe enfrentar problemas, avaliar e propor teorias e argumentos - que sabe, em suma, por si só - é um cidadão criativo e crítico, elementos sine qua non para uma sociedade próspera. (MURCHO, 2002, p. 1)
\end{abstract}

Fica evidente que os objetivos da sociedade pós-ditatura são totalmente contrários aos objetivos da sociedade presentes no regime militar. Por isso, fez-se necessário encontrar novas maneira de educar as novas gerações e vários paradigmas educacionais foram sendo propostos ao longo dos tempos, sempre buscando encontrar formas mais eficazes de melhoria do ensino no Brasil.

\title{
4 DOCÊNCIA E CURRÍCULO
}

Forquin (1992) propõe a utilização do termo currículo para designar aquilo que é selecionado enquanto conteúdo escolar a ser aprendido. A escola não apenas faz seleções curriculares, também possui a função de se tornar transmissível e assimilável uma tradição cultural. A escola é a responsável pela transposição didática, ou seja, dar integibilidade ao conhecimento socialmente adquirido e selecionado. A transposição didática deve levar em 
EDUCAÇÃO, ENSINO E DOCÊNCIA: REFLEXÕES E PERSPECTIVAS

consideração não apenas o estado do conhecimento a ser transmitido, mas também o estado daquele que ensina e daquele que aprende. Ressalta-se a importância de discernimento entre aquilo que é pretendido e aquilo que realmente é ensinado, o que de fato é objeto de pesquisa e de investigação. São equívocos os apegos didáticos, as regras e sanções concernentes ao ordenamento e o disciplinamento da atividade escolar que muitas vezes possuem maior importância que a própria cultura escolar. Essa didatização, esse ordenamento incide sobre a escola, sobretudo no que tange a seleção dos conteúdos escolares que preconizam processos de esquematização e memorização. A escola quando toma ciência de seu lugar como produtora de saberes originais supera o esquematismo. A escola quando instituída em padrões democráticos promove a integração reflexiva e não passiva à ordem social.

O conhecimento selecionado e organizado para veiculação na escola nunca foi e continua não sendo neutro. É fruto da seleção de conteúdos, princípios e valores que provém de grupos hegemônicos da sociedade. Assim, torna-se importante compreender porque o conhecimento desses grupos é sempre primeiramente representado nas escolas e que interesses sociais, políticos e ideológicos (critérios) orientam a seleção e formatação da prática pedagógica. Interesses econômicos e ideológicos incorporaram compromissos com estruturas e políticas educacionais que contribuíram historicamente para a promoção das desigualdades sociais.

\footnotetext{
As escolas não controlam apenas as pessoas; elas também ajudam a controlar significados. Desde que preservam e contribuem o que é considerado como o "conhecimento legítimo" - o conhecimento que "todos devemos ter" - as escolas conferem legitimação cultural ao conhecimento de grupos específicos. Mas isso não é tudo, pois a capacidade de um grupo tornar seu conhecimento em "conhecimento para todos" está relacionada ao poder desse grupo no campo de ação político e econômico mais amplo. Poder e cultura, então, precisam ser vistos, não como entidades estáticas sem conexão entre si, mas como atributos das relações econômicas existentes em uma sociedade. Estão dialeticamente entrelaçados, de modo que poder e controle econômico estão interligados com poder e controle cultural. (APPLE, 1982, p. 98)
}

Os saberes escolares representam, sobretudo em seu processo de seleção, uma gama de relações hierarquizadas de estratificação, que em suma denotam as relações de poder implícitas e explicitas na prática escolar. No tocante ao conhecimento educacional pode-se utilizar o mesmo raciocínio. O conhecimento também se relaciona de forma intrínseca com as relações de poder, sobretudo no que se refere ao controle do "real", ou seja, nas adequações e dinâmicas daquilo que é realidade, e também na validação para que essa mesma realidade seja 
MARQUES, S.; OLIVEIRA, T.

aceita como verdade enquanto discurso sociopolítico. O poder tem um caráter dual, se referindo tanto à capacidade de ação efetiva, dentro de uma perspectiva direta e impositiva, como também pode ser considerado uma forma de atuação coletiva e democrática. Dentro dessa perspectiva as massas populares devem ser inseridas na ampliação das ações para o alfabetismo crítico ${ }^{3}$ como forma de inserção democrática e cidadã.

A realidade não é algo axiomático, mas sim socialmente construída. Um exemplo elucidativo é a escola como instituição social. A escola, ao romper com as práticas totalizantes passa expressar a construção democrática, rompe com os processos de controle. É necessário então refletir acerca da legitimação e da validação do conhecimento na escola, principalmente investigando quem este conhecimento deve representar (SACRISTAN, 2000). Assim, a educação se converte em uma importante ferramenta para o desvelamento da realidade, a partir de uma proposta de alfabetização cultural e crítica mais ampla. Em um mundo globalizado, a prática educativa não pode ser óbvia, devendo ter clareza de sua perspectiva interdisciplinar e de provisão do diálogo. A prática educativa deve, na sua construção, englobar a dinâmica das questões e dos problemas que afligem a sociedade, uma vez que o sujeito, ao participar da transformação das esferas que lhe garantem segurança como o Estado, a sociedade e o mundo do trabalho - participa também da construção da sua própria subjetividade.

Para Apple (1982) a organização e o controle das práticas curriculares de uma determinada sociedade, principalmente no que tange ao processo de educação e escolarização dentro de uma formação social, é muitas vezes pautado pela homogeneização. Entende-se por homogeneização a intervenção política, social, econômica e cultural em uma formação social com o intuito de organizar o sistema produtivo, massificando e aculturando o indivíduo, para garantir a efetivação e cumprimento dos interesses de uma classe social, cerceando assim a percepção das contradições existentes entre as classes. Deste modo o currículo e a escola se tornam reprodutores da desigualdade social, mas, sobretudo, representantes da ordem social vigente. Em suma, as reflexões acerca do currículo são necessárias para que a escola sofra as devidas mudanças em sua estrutura ideológica e pedagógica, a fim de desenvolver um processo educativo que possa proporcionar ao indivíduo sua inserção reflexiva na sociedade.

\section{DOCÊNCIA E AFETIVIDADE}

\footnotetext{
${ }^{3}$ Processo de emancipação crítica e reflexiva do sujeito. Revista Reflexão e Ação, Santa Cruz do Sul, v. 24, n. 3, p.189-211, Set./Dez. 2016. http://online.unisc.br/seer/index.php/reflex/index
} 
EDUCAÇÃO, ENSINO E DOCÊNCIA: REFLEXÕES E PERSPECTIVAS

Décadas se passaram e o paradigma tradicional perdura, numa aparente recusa em não acatar novas demandas educacionais e posicionamentos didático-pedagógicos que envolvem, entre outros elementos, a afetividade. Freire defendeu que existe uma espécie de mito na relação entre seriedade docente e afetividade, ou seja, "serei tão melhor professor quanto mais severo, mais frio, mais distante e "cinzento" me ponha nas minhas relações com os alunos, no trato dos objetos cognoscíveis que devo ensinar" (2002, p. 160). Porém, Freire explica que a afetividade não pode ser separada da cognoscibilidade, isto é, daquilo que se pode conhecer, o que não pode acontecer é permitir que a afetividade do docente interfira no cumprimento ético do seu dever quando exerce sua autoridade. Freire também considera falsa a ideia de que seriedade docente e alegria são incompatíveis, como se a demonstração de alegria de um docente fosse sinônimo de menos rigor ou competência. E conclui,

\footnotetext{
A prática educativa é tudo isso: afetividade, alegria, capacidade científica, domínio técnico a serviço da mudança ou, lamentavelmente, da permanência do hoje. É esta permanência do hoje neoliberal que a ideologia contida no discurso da "morte da História" propõe. Permanência do hoje a que o futuro desproblematizado se reduz. Daí o caráter desesperançoso, fatalista, antiutópico de uma tal ideologia em que se forja uma educação friamente tecnicista e se requer um educador exímio na tarefa de acomodação ao mundo e não na de sua transformação. Um educador com pouco de formador, com muito mais de treinador, de transferidor de saberes e examinador de destrezas. (FREIRE, 2002, p. 143)
}

Tendo em vista todos os elementos aqui apontados como passíveis de influenciar a atuação docente, parece evidente que a mudança de paradigmas e de conceitos didáticopedagógicos pode ser fortemente determinada por uma mudança de atitude docente. Como vimos, a "morte da História", ou seja, a morte de um sonho ou a imobilidade do Homem, deveria ser um estímulo no sentido de resgatarmos a utopia de práticas educativas humanizantes. Ao desconsiderar totalmente a formação integral do ser humano, estamos reduzindo o ensino a puro treinamento e a fortalecer as relações de autoridade verticalizada. Perpetua-se, então, a exclusão de formas de desenvolvimento da autonomia e do sentido crítico do indivíduo, o que é, per se, redutor e limitante.

Assim, resta ao docente refletir sobre o tipo de educador que ele/ela escolhe ser, sem retirar da equação o fato de que, em última instância, a aula é para o aluno, logo, o docente deverá ter sempre em mente seus interesses e necessidades.

\section{DOCÊNCIA E EMANCIPAÇÃO HUMANA}


Em Sobre a Pedagogia, Kant reafirma a importância da razão no desenvolvimento da criticidade, que em seu cerne intrínseco é uma operação dialético-reflexiva. A educação para Kant seria o processo capaz de dotar o homem de humanidade e, portanto, alcançar o ideal iluminista de progresso. Ora, e qual seria este ideal de progresso? Para Kant o progresso residia no desenvolvimento do potencial humano e técnico que de fato levaria a própria humanidade a um estágio melhor. A educação racional mediante a perspectiva kantiana prepara o homem para o devir. Percebe-se o caráter moral e subjetivo da razão, pois existe a preocupação com a educação moral, ou seja, a preparação para o viver, para a inserção do indivíduo na coletividade, enquanto que para o filosofo alemão a educação incide sobre a autonomia e o esclarecimento que são processos subjetivos.

Talvez a educação se torne sempre melhor a cada uma das gerações futuras dê um passo a mais em direção ao aperfeiçoamento da humanidade, uma vez que o grande segredo da perfeição da natureza humana se esconde no problema da educação. É entusiasmante pensar que a natureza humana será sempre melhor desenvolvida e aprimorada pela educação e que é possível chegar a dar aquela forma, a qual em verdade convém à humanidade. Isso abre a perspectiva de uma futura felicidade da espécie humana. (KANT, 1996, p.16).

Então, para Kant a pedagogia e o processo educacional concernem o aprimoramento da humanidade, numa concepção de formação que está na base do conceito de Bildung, ou seja, a formação do sujeito pleno e esclarecido, capaz de pensar por si mesmo, em termos críticos e reflexivos, como premissa essencial da teoria pedagógica. A educação seria o aperfeiçoamento da natureza humana em prol da felicidade individual e coletiva, portanto uma prática social que diferencia os homens dos animais irracionais. Apenas o homem é capaz de transmitir a gerações futuras uma tradição cultural, que apropriada poderá contribuir para o progresso humano e material.

A educação é uma arte, cuja prática necessita ser aperfeiçoada por várias gerações. Cada geração de posse dos conhecimentos das gerações procedentes está sempre melhor aparelhada para exercer uma educação que desenvolva todas as disposições naturais na justa proporção e de conformidade com a finalidade daquelas e assim, guie toda humana espécie ao seu destino. (KANT, 1996, p.19).

A considerar a educação uma arte, Kant a referenda como uma prática essencialmente humana. Apenas o homem é capaz de dar significação a símbolos e conceitos diversos por meio da faculdade da razão. Segundo a perspectiva kantiana " [...] somente a produção por liberdade, isto é, por um arbítrio, que toma como fundamento de suas ações a razão, deveria Revista Reflexão e Ação, Santa Cruz do Sul, v. 24, n. 3, p.189-21 1, Set./Dez. 2016.

http://online.unisc.br/seer/index.php/reflex/index 
EDUCAÇÃO, ENSINO E DOCÊNCIA: REFLEXÕES E PERSPECTIVAS

denominar-se arte." (KANT, 1980, p. 243). A arte em seu cerne é uma atividade eminente e apenas humana e distintora da espécie quanto às outras. Para o filósofo alemão, a educação se configura como um dos mais árduos problemas proposto aos homens, pois o próprio conceito de educação é dialético à medida que se consolida na transmissão de uma herança cultural de uma geração para outra, que mediante a historicidade do seu viver não transmitirá a mesma herança, mas sim uma herança agregada pela experiência histórica. Kant concebe uma teoria pedagógica fundada na percepção crítica da razão, e na transmissão da herança cultural, que corresponde ao conhecimento. No entanto esse conhecimento não é estático, mas dialético, uma vez que a reflexão crítica e a produção material que é temporal permitem no processo de humanização não a reprodução do mesmo, mas sim o advento do novo. Daí o caráter pedagógico do pensamento kantiano, pois não se deve educar em prol do presente, mas sim de um estado melhor, de um possível futuro. Para que isso ocorra faz-se necessário aprender a pensar, refletir acerca do próprio pensamento. A reflexão autônoma é emancipadora e afasta o homem da animalidade, da barbárie. Estrutura-se dessa maneira o conceito de liberdade em Kant, que [...] é o poder de conciliar a submissão ao constrangimento das leis com o exercício da liberdade. (KANT, 1996, p. 32). O constrangimento é necessário, pois a educação também é um processo moral, não se pode alijar o disciplinamento do processo pedagógico, afinal a autonomia é subjetiva, mas sempre inserida em um contexto social. $\mathrm{O}$ constrangimento das leis deve ter como finalidade educar para o uso da liberdade.

\section{O DESAFIO DAS TECNOLOGIAS: MUDANDO O CONCEITO DE AULA}

O fenômeno da globalização, o desenvolvimento acelerado das tecnologias, comunicação de massas e difusão de conhecimento são elementos intrinsecamente ligados e que se interinfluenciam continuamente. Porém, suas consequências ainda não impactaram plenamente o ensino de todos os países.

Todavia, no Brasil circulam já vários termos, que são consequência direta das tecnologias aplicadas à educação, como "educação à distância", "aprendizagem à distância" e "ensino à distância”. Os dois primeiros termos são passíveis de discussão, já que "educação" e "aprendizagem" são considerados processos que ocorrem dentro do indivíduo, logo, não podem ser realizados "à distância", enquanto que "ensino" pode ser feito de forma não presencial (CHAVES, 1999). Tradicionalmente fazia-se ensino à distância através de cartas 
MARQUES, S.; OLIVEIRA, T.

(como as epístolas do Novo Testamento da Bíblia Sagrada) e de livros, o que se denomina de baixa tecnologia.

Hoje, as tecnologias e a Internet colocam ao nosso alcance uma gama infinita de informações e conhecimentos, praticamente em qualquer parte e a qualquer hora, o que representa a grande novidade educacional do início do milênio. A educação opera, sobretudo, com a linguagem escrita e a nossa cultura já se deixou impregnar pela linguagem da televisão e da Internet. Os jovens adaptam-se com mais facilidade do que os adultos ao uso do computador, pois estão nascendo na era da cultura digital.

\section{CONTEXTO ATUAL}

A velocidade de desenvolvimento tecnológico acelerado faz com que os sistemas educacionais, ou não consigam acompanhar o ritmo, ou ainda não avaliem eficazmente o impacto da comunicação audiovisual e da informática. Uma possível consequência é a resistência dos professores às tecnologias e ao abandono de metodologias e recursos pedagógicos tradicionais, que já não têm apelo para a nova geração de alunos. Os defensores da informatização da educação defendem que é necessário mudar profundamente os métodos de ensino para reservar ao cérebro humano o que lhe é peculiar, a capacidade de pensar, em vez de desenvolver a memória. Para eles, a função da escola será, cada vez mais, a de ensinar a pensar criticamente. Para isso é preciso dominar mais metodologias e linguagens, inclusive a linguagem digital (GADOTTI, 2000).

Perante o expressivo volume de informações atual, é pertinente refletir sobre a nossa capacidade de filtrar as informações que, de fato, são relevantes, bem como ajuizar o modo como a escola está ajudando a nova geração a desenvolver o seu poder crítico. De acordo com Morin (2000), a educação do futuro deve promover a inteligência geral para sabermos usar os conhecimentos e ter capacidade de colocar e resolver problemas complexos e essenciais nesse processo de conhecimento. Quanto mais desenvolvermos as habilidades gerais e quanto mais aptos estivermos para resolver problemas genéricos, mais iremos desenvolver habilidades particulares e mais aptos estaremos para resolver problemas pontuais. Além deste posicionamento, verificamos ainda que Morin critica o ensino por disciplinas, fragmentado e dividido, por este dificultar a capacidade natural que o espírito tem de contextualizar o conhecimento. Esta capacidade deve ser incentivada e desenvolvida pelo ensino, estimulando o aluno a ligar as partes ao todo e o todo às partes. A promoção do conhecimento que vincula 
EDUCAÇÃO, ENSINO E DOCÊNCIA: REFLEXÕES E PERSPECTIVAS

as partes e o todo compreende que um é pertinente ao outro e que estes se integram e se complementam. Destarte, Morin defende o multidimensional como algo indispensável para o conhecimento pertinente, pois as partes não podem ser dissociadas nem isoladas do todo. Ele nos explica que "o ser humano é ao mesmo tempo biológico, psíquico, social, afetivo e racional. A sociedade comporta as dimensões histórica, econômica, sociológica, religiosa" (MORIN, 2000, p. 38), deixando implícito que as conjunturas e os contextos do conhecimento devem estar em completa organicidade e sistematização.

Não é difícil concluir que este posicionamento está distante da realidade da maioria das escolas, o que se configura num sério desafio para as escolas e professores da atualidade. Como lidar com o conhecimento teórico na era da informação? Como ensinar alunos do século XXI inseridos num sistema educativo do século XIX, familiarizados com realidades virtuais complexas e imbuídos de uma cultura enriquecida por tecnologias da informação e comunicação em incessante desenvolvimento? Como podemos pensar as atuais práticas de ensino e aprendizagem numa sociedade em acelerada mudança? Então, como poderia se configurar a educação na era digital? Libâneo nos aponta algumas possibilidades. Em primeiro lugar, ele argumenta que a tecnologia digital não pode substituir a pedagogia e acrescenta que "as características de todo bom professor precisam ser identificadas a partir de sua base pedagógica. Não são as tecnologias digitais que as definem e nem apenas as demandas da escola do futuro" (2013, p.1). Ele vai mais além e defende que a prática docente deve contemplar três predicados fundamentais: dominar a matéria que ensina, saber como ensinar os conteúdos e identificar as necessidades individuais de cada estudante. Esses atributos são essenciais para atender a demandas educacionais contemporâneas como inter alia, formar sujeitos com capacidade reflexiva, capazes de fundamentar e lidar criticamente com a informação e a produção própria de conteúdo utilizando a palavra, a imagem, o movimento, o hipertexto. Somente após conjugar todos estes elementos essenciais é que podemos considerar que as tecnologias digitais têm uma contribuição maior a dar à prática docente. Todavia, é inadmissível uma prática docente centrada no uso de tecnologias para o desenvolvimento de habilidades, porém, desvinculada do seu contexto e significado:

Elas [as tecnologias], dessa forma, praticamente não contribuem para o desenvolvimento das capacidades intelectuais e a formação da personalidade dos estudantes. É necessário o domínio da linguagem informacional, habilidade de articular as aulas com as mídias e multimídias, as lógicas e modos de lidar com o conhecimento das tecnologias (LIBÂNEO, 2013, p.1). 
MARQUES, S.; OLIVEIRA, T.

Em última instância, verificamos que, apesar dos atuais avanços tecnológicos e dos inequívocos subsídios que a utilização das TIC pode trazer para o processo ensinoaprendizagem dentro da escola do século XXI, ainda vale ressaltar que há componentes clássicos essenciais inerentes a uma profissão docente de qualidade. O conhecimento pedagógico do conteúdo é algo que ainda distingue um excelente professor de outro que apenas sabe a sua disciplina. Este é também um professor que sabe como transformar seu conhecimento da matéria em atividades e experiências que estimulam, envolvem e melhoram a aprendizagem ativa e a compreensão dos alunos (SHULMAN, 2005). Além do mais, o processo de assimilação dos conhecimentos na forma de conceitos demanda dos alunos mudanças no seu desenvolvimento psíquico, o que origina novas aptidões intelectuais para a apropriação de conhecimentos de nível mais complexo. Assim, o conhecimento didático docente é condição sine qua non para auxiliar o aluno a mobilizar suas habilidades intelectuais de forma a apreender conceitos. Para tal, o professor deve ter bom domínio dos conteúdos, bem como dos métodos e procedimentos investigativos da ciência ensinada, para assim se verificar a total simbiose entre conhecimento disciplinar e conhecimento pedagógico (LIBÂNEO, 2015).

\section{CONSIDERAÇÕES FINAIS}

A percepção da experiência educacional é aguçada a partir da vivência prática. Mais do que uma proposição retórica, a educação e o ensino devem permitir em sua materialização a autonomia e a humanização do sujeito, por meio do diálogo crítico e da reflexão que promove o Bem - dessa forma a educação deve objetivar a liberdade e a promoção da capacidade de reflexão crítica e emancipação dos indivíduos. A educação deveria então se configurar como ferramenta para a humanização, contra a massificação e a alienação, promovendo a formação de cidadãos plenos, esclarecidos e preparados para a vida democrática. Um projeto educacional não é nada mais do que a materialização coletiva de experiências pedagógicas que possam permitir ao professor e ao educando uma experiência dialógica e reflexiva. $\mathrm{O}$ conceito de educar revela, na prática pedagógica, o processo intencional, planejado e permanente no qual alguém conduz outro alguém para seu crescimento social e cultural, algo intimamente associado ao ensino e socialização (LUZURIAGA, 1975). Para que o sujeito se eduque, ele deve desenvolver formas de definir e decidir por si mesmo o que é melhor para ele e para o outro. Para isso a formação docente e a prática pedagógica do professor devem se amalgamar no processo de crescimento dos diversos sujeitos envolvidos no processo Revista Reflexão e Ação, Santa Cruz do Sul, v. 24, n. 3, p.189-211, Set./Dez. 2016.

http://online.unisc.br/seer/index.php/reflex/index 
EDUCAÇÃO, ENSINO E DOCÊNCIA: REFLEXÕES E PERSPECTIVAS

educacional, no que tange ao ensino-aprendizagem, na direção da sua emancipação. É neste âmbito que educar e ensinar se coadunam e precisam ser entendidos.

O conceito de ensinar não se restringe a uma simples transmissão de conhecimento e informações de cunho acadêmico durante as aulas. Essa dimensão abarca todo o processo de mediação do conhecimento para que na escola sejam viabilizadas situações efetivas de aprendizagem para o aluno, que assegurem seu acesso ao conhecimento. Independentemente da metodologia de ensino ou dos recursos didáticos utilizados, essa é a função social do professor. Mesmo com as mudanças na dinâmica da profissão docente, consequências da acelerada transformação social e sua interferência na escola e no modo de agir do professor, ensinar continua sendo função da escola e responsabilidade do professor. Sem acesso ao conhecimento não é possível o acesso à formação. Se a educação como categoria significa um meio para que as pessoas se incluam numa sociedade concreta, a formação docente em sua práxis está associada ao desenvolvimento da consciência própria, à condição do sujeito de fazer uso do seu potencial de razão, de tornar-se emancipado. Qualquer experiência educacional verticalizada e tutelada pelo professor de forma autoritária está fadada ao fracasso. É necessário conferir poder aos educandos. A práxis educativa que objetiva promover a cidadania e a democracia em seu nascedouro precisa ser fruto de uma prática educativa que prime pela educação, pelo ensino e pela formação - apenas assim a educação concretizará a formação de sujeitos autônomos.

A produção do conhecimento educacional e do conhecimento docente deve superar a mera acumulação de opiniões, deve superar o delimitado no senso comum. Romper com o senso comum de maneira nenhuma significa a desconsideração da experiência e dos saberes dos educandos, mas sim a constante construção-reconstrução do olhar acerca dos objetos pesquisados durante a ação pedagógica através do diálogo e do confronto entre os paradigmas teóricos que sustentam a análise dos alunos. Essa problematização constante incide, não em uma ruptura simples e objetiva, mas na retomada crítica, em um processo constante de vigilância epistemológica, que considera as noções e conceitos presentes na prática cotidiana do professor e dos seus alunos.

Educar e ensinar carece ter como objetivos primazes a formação do cidadão, do sujeito pleno capaz de pensar por si mesmo. É neste processo que a educação e o ensino se efetivam. Para isso, professor e aluno devem deixar de ser entes meramente contemplativos e passar a compreender a importância da reflexão acerca da realidade histórica, social e cultural. Uma pergunta se faz pertinente. O que seria esta realidade? A realidade é construída mediante 
MARQUES, S.; OLIVEIRA, T.

experiências subjetivas e coletivas, através da ação humana no tempo. O desenvolvimento dessa percepção na sala de aula é que permitirá ao educando a sua inflexão enquanto sujeito histórico. Assim, a prática pedagógica deve ser sempre formativa e democrática, pois somente dessa maneira se forma o cidadão pleno e emancipado. Não se nasce cidadão, torna-se cidadão. Uma consciência cidadã verdadeira só pode ser forjada a partir de uma experiência educacional formativa, em que a educação, o ensino e a formação não sejam trabalhados como conceitos díspares, mas sim como constituintes norteadores da escola e materializados na práxis educativa. Privar sujeitos, seja professor ou aluno, de uma formação plena é impedir o fomento da cidadania e da democracia.

\title{
EDUCATION, TEACHING AND TEACHING PRACTICE: ANALYSES AND
}

\section{VIEWPOINTS}

\begin{abstract}
This text aims to analyze the teaching profession in its various educational perspectives. The motivation to write this article sprang from the need to understand how education, teaching and teaching practices can be critically involved in generating whole citizens, i.e., autonomous individuals that can think for themselves. The aim is to find an educational practice of possibility, which signals an education that enables a more righteous and equitable world, one that does not succumb to the constraints of massification. Nowadays we often notice the weakening of human bonds within the educational process, especially regarding the relationship between teaching practices and education. Thus, we intend to distinguish education from teaching, based on the pedagogical theory and history of education. We seek to reiterate the importance of teacher training and teachers' role, in order to induce a critical, liberating and interchanging type of education.
\end{abstract}

Key words: Education; Teaching; Teacher Training; Teacher

\section{EDUCACIÓN, ENSEÑANZA Y LA PROFESIÓN DOCENTE: REFLEXIONES Y}

\section{PERSPECTIVAS}


EDUCAÇÃO, ENSINO E DOCÊNCIA: REFLEXÕES E PERSPECTIVAS

\section{Resumen}

El objetivo de este artículo es el análisis de la profesión docente en sus distintas perspectivas educativas. El presupuesto para la construcción del artículo fue reflexionar como la educación, la enseñanza y la docencia pueden materializarse a la manera de crítica en la formación del ciudadano pleno, o sea, lo sujeto autónomo que piensa por si propio. Se busca una práctica educacional de la posibilidad, una educación que posibilite un mundo más justo e igual que no se someta a las amarras de la masificación. En la contemporaneidad se percibe un daño patente de las relaciones humanas dentro del proceso educativo, sobre todo con respecto a relación docencia y enseñanza. Se busca diferenciar lo que, de hecho, es educación y lo que es enseñanza en un análisis fundamentada en la teoría pedagógica y en la historia de la educación. De dentro de esa perspectiva se procura la reiteración de la importancia de la formación docente y del papel del maestro, en un movimiento de promoción de una educación de cambio crítica y libertadora.

Palabras clave: Educación; Enseñanza; Formación Docente; Maestros.

\section{REFERÊNCIAS}

APPLE. Michael. Ideologia e currículo. São Paulo: Editora Brasiliense, 1982.

BRANDÃO, Carlos Rodrigues. O que é educação. 49. ed. São Paulo: Editora Brasiliense, 2007.

CHAVES, Eduardo. Ensino a distância: conceitos básicos. Universidade Estadual Paulista, 1999. Disponível em: <http://www.feg.unesp.br/ saad/zip/EADConceitosBasicos.htm>. Acesso em: 01 ago. 2016.

FORQUIN, Jean. Saberes escolares, imperativos didáticos e dinâmicas sociais. Teoria \& Educação, Porto Alegre, n. 5, p.28-49, maio/ago 1992.

. Pedagogia do oprimido. 3. ed. Rio de Janeiro: Paz e Terra, 1975.

. Educação e mudança. Rio de Janeiro: Paz e Terra, 1983.

Política e educação. 5. ed. São Paulo: Cortez, 1995. 
MARQUES, S.; OLIVEIRA, T. Terra, 1996.

Pedagogia da autonomia. Saberes necessários à prática educativa. São Paulo: Paz e

. Pedagogia da esperança: um reencontro com a pedagogia do oprimido. 8. ed. Rio de Janeiro: Paz e Terra, 2001.

. Pedagogia da autonomia: saberes necessários à prática educativa. 25. ed. São Paulo: Paz e Terra, 2002.

FREIRE, P.; SHOR, I. Medo e ousadia: o cotidiano do professor. 5. ed. Rio de Janeiro: Paz e Terra, 1986.

GADOTTI, Moacir. Perspectivas atuais da educação. São Paulo em Perspectiva, n. 2, 2000. v. 1.

KANT, Immanuel. Introdução à crítica do juízo. In: Os Pensadores. São Paulo: Editora Abril, 1980.

. Sobre a pedagogia. São Paulo: Editora UNIMEP, 1996.

LIBÂNEO, José Carlos, “Tecnologia digital não pode substituir pedagogia”, diz professor. Fonte: UOL Educação online, publicada em 23/05/2013. Disponível em:

$<$ http://educacao.uol.com.br/noticias/2013/05/23/tecnologia-digital-nao-pode-substituirpedagogia-diz-professor.htm>. Acesso em: 30 ago. 2016.

. Formação de Professores e Didática para Desenvolvimento Humano. Educação \& Realidade, Porto Alegre: UFRGS/FACED, vol. 40, n. 2, p. 629-650, abr./jun. 2015.

LIBÂNEO, J. C.; OLIVEIRA, J. F.; TOSCHI, M. S. Educação escolar: políticas estrutura e organização. 2. ed. São Paulo: Cortez, 2005.

LUZURIAGA, Lorenzo. História da educação e da pedagogia. São Paulo: Cia Editora Nacional, 1975.

MANACORDA, Mario. História da Educação: da antiguidade aos nossos dias. 3. ed. São Paulo: Cortez, 1992.

MORAN, José Manuel. Ensino e aprendizagem inovadores com tecnologias audiovisuais e telemáticas. In: MORAN, J.; MASETTO, M.; BEHRENS, M. Novas tecnologias e mediação pedagógica. Campinas, São Paulo: Papirus, 11- 66, 2000.

Novos desafios na educação: a internet na educação presencial e virtual. Pelotas, 2001. [Internet] Disponível em:

$<$ http://www.eca.usp.br/prof/moran/site/textos/tecnologias_eduacacao/novos.pdf $>$. Acesso em: 01 jan. 2016.

MORIN, Edgar. Os sete saberes necessários à educação do futuro. 3. ed. São Paulo: Cortez, Brasília: UNESCO, 2001. 
EDUCAÇÃO, ENSINO E DOCÊNCIA: REFLEXÕES E PERSPECTIVAS

MURCHO, Desidério. Os novos paradigmas da educação. Jornal Público (Portugal), 2002. [Internet] Disponível em: 〈http://criticanarede.com/ed02.html〉. Acesso em: 01 ago. 2016.

NÓVOA, Antônio. (Org.). Vidas de professores. Porto: Porto Editora, 1992. . Os professores e sua formação. Lisboa: Dom Quixote, 1995. . Profissão professor. Porto: Porto Editora, 1995.

Para o estudo sócio-histórico da gênese e desenvolvimento da profissão docente. In: Dossiê: interpretando o trabalho docente, Revista Teoria \& Educação, Porto Alegre: Pannonica Editora Ltda, n. 4, 109-139, 1991.

PARO, Vitor. Educação como exercício do poder: crítica ao senso comum em educação. São Paulo: Cortez, 2008.

PERRENOUD, Philippe. A prática reflexiva no ofício de professor: profissionalização e razão pedagógica. Porto Alegre: Artmed, 2002.

SACRISTÁN, José Gimeno. O currículo: uma reflexão sobre a prática. Porto Alegre: Artmed, 2000.

SAVIANI, Demerval. Trabalho e educação: fundamentos ontológicos e históricos. Revista Brasileira de Educação, Rio de Janeiro: ANPED; Campinas: Autores Associados, vol. 12, n. 34, 152-180, 2007.

Entrevista Demerval Saviani: educação é a força motriz da economia. Revista Educação online da CONTEE, Brasília: Confederação Nacional dos Trabalhadores em Estabelecimentos de Ensino, 12 Nov de 2008. Disponível em:

<http://www.contee.org.br/noticias/educacao/nedu752.asp>. Acesso em: 01 ago. 2016.

SILVA, Miriam. O computador na perspectiva do desenvolvimento profissional do professor. 1997. 140 f. Tese (Doutorado em Educação) - UNICAMP, Campinas.

SPOHR, Albino. A diferença entre ensino e educação. Gazeta Zero Hora, Porto Alegre, 17 out. de 2006. Disponível em: <http://www.sersel.com.br/imprensa_releases_17.asp>. Acesso em: 01 ago. 2016.

VALENTE, José Armando. Aprendendo para a vida: o uso da informática na Educação Especial. In: F. M. P. FREIRE; J. A. VALENTE (Orgs.). Aprendendo para a vida: os computadores na sala de aula. São Paulo: Cortez, 2001.

Data de recebimento: $18 / 03 / 2016$

Data de aceite: 12/09/2016 